\title{
LAUR- $96-4524$
}

ASSESSMENT OF THE COMPOSITIONAL INFLUENCES ON THE TOUGHNESS OF $\mathrm{TICr}_{2}$-BASE LAVES PHASE ALLOYS

Katherine C. Chen*, Samuel M. Allen, and James D. Livingston

Massachusetts Institute of Technology, Dept. of Mat. Sci. and Eng., Cambridge, MA 02139

*now at Los Alamos National Laboratory, MS-G755, Los Alamos, NM 87545, kchen@lanl.gov

ABSTRACT

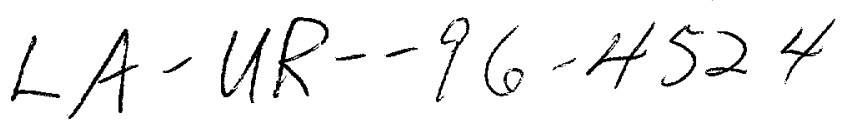

Systematic studies of alloys based on $\mathrm{TiCr}_{2}$ have been performed in order to improt toughness of Laves phase intermetallics. The extent to which alloy compositions and annealing treatments influence the toughness was quantified by Vickers indentation. The single-phase Laves behavior was first established by studying stoichiometric and nonstoichiometric $\mathrm{TiCr}_{2}$. Next, alloying effects were investigated with ternary Laves phases based on $\mathrm{TiCr}_{2}$. Different microstructures of two-phase alloys consisting of $(\mathrm{Ti}, \mathrm{Cr})-\mathrm{bcc}+\mathrm{TiCr}_{2}$ were also examined. Various toughening theories based on vacancies, site-substitutions, crystal structure $(C 14, C 36$, or $C 15$ ) stabilization, and the presence of a second phase were evaluated. The most effective factors improving the toughness of $\mathrm{TiCr}_{2}$ were determined, and toughening mechanisms are suggested.

\section{INTRODUCTION}

While several studies have addressed the problem of brittleness in Laves phases, basic understanding of which factors affect the toughness and to what extent toughness can be improved, has not been well documented for this particular class of intermetallics. The first reports of deformation in a Laves phases were $\mathrm{HfV}_{2}$-base compounds in a two-phase alloy that could be rolled at room temperature without cracking [1]. Livingston and Hall [2] proceeded to show by TEM that $\mathrm{HfV}_{2}$ Laves phases displayed increased twinning with additions of $\mathrm{Nb}$ and $\mathrm{Ti}$. They suggested that alloying to substitute on both sublattices of the intermetallic and/or that lowering the stacking fault energies could improve the toughness of Laves phases. Alloying elements [3] or vacancies [4] may affect the synchroshear deformation process, and thus potentially improve the mechanical properties. Much work has also been done on two-phase Laves systems $[5,6]$ to evaluate their potential as structural materials.

This study attempted to understand and quantify changes in the fracture toughness due to different factors in a single Laves system. Several different alloys based on the $\mathrm{TiCr}_{2}$ Laves phase were examined. The role of defects and stoichiometry are addressed in the first section concerning the single-phase Laves alloys. Alloying element site occupancy and crystal structure stabilization are then investigated in ternary $\mathrm{TiCr}_{2}$-base Laves phases. Finally, two-phase systems of $\mathrm{TiCr}_{2}$ in a Ti-rich and a Cr-rich bcc solid solution are studied. Comparisons are made in order to help direct future development of Laves phase alloys.

\section{EXPERIMENTAL PROCEDURES}

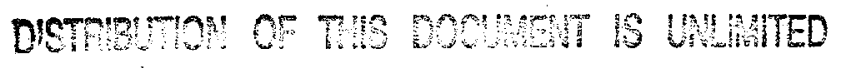
$\rightarrow 0$

The alloys were arc-cast and subjected to various homogenization and annealing treatments. Anneals at and above $1200^{\circ} \mathrm{C}$ were performed in a vacuum furnace and oilquenched. Nominal compositions and phases of the alfoysamples can be found in Table I.

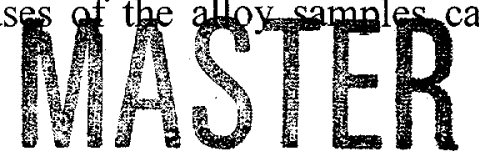




\section{DISCLAIMER}

Portions of this document may be illegible in electronic image products. Images are produced from the best available original document. 


\section{DISCLAIMER}

This report was prepared as an account of work. sponsored by an agency of the United States Government. Neither the United States Government nor any agency thereof, nor any of their employees, make any warranty, express or implied, or assumes any legal liability or responsibility for the accuracy, completeness, or usefulness of any information, apparatus, product, or process disclosed, or represents that its use would not infringe privately owned rights. Reference herein to any specific commercial product, process, or service by trade name, trademark, manufacturer, or otherwise does not necessarily constitute or imply its endorsement, recommendation, or favoring by the United States Government or any agency thereof. The views and opinions of authors expressed herein do not necessarily state or reflect those of the United States Government or any agency thereof. 


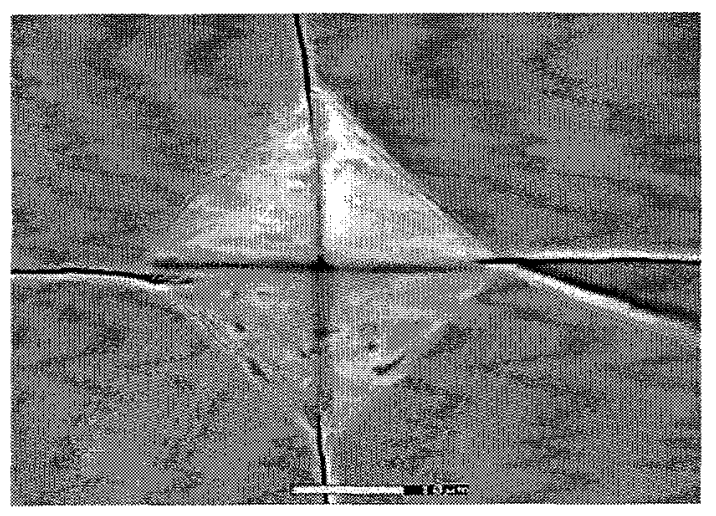

Figure 1. SEM micrograph of radial cracks from the indentation impression corners of a $(\mathrm{Ti}, \mathrm{Nb}) \mathrm{Cr}_{2}$ ternary Laves alloy.
Standard metallographic procedures were used, and compositions were determined by electron microprobe analysis (EMPA). Phases and lattice constants were determined by $\mathrm{x}$-ray diffraction (XRD) and transmission electron microscopy (TEM). Vickers indentations were made at room temperature and then measured with an environmental scanning electron microscope (ESEM). Figure 1 is an SEM micrograph depicting typical radial cracks originating from the indentation impression corners. Toughness values were computed from average crack lengths, following equations by Antis, et al. [7]. Roomtemperature compression tests of the two-phase alloys were performed with a crosshead speed of $0.0025 \mathrm{~cm} / \mathrm{min}$.

Table I. Nominal Compositions (at \%) and Phases of Alloy Samples.

\begin{tabular}{|l|l|l|}
\hline Nominal Alloy Composition & Annealing Treatments & Phases \\
\hline Single-Phase Binary Alloys & & \\
Ti-62 Cr & $1300^{\circ} \mathrm{C}, 1200^{\circ} \mathrm{C}, 1000^{\circ} \mathrm{C}$ & $C 14+\beta, C 36+\beta, C 15+\beta$ \\
Ti-64 Cr & $1300^{\circ} \mathrm{C}, 1200^{\circ} \mathrm{C}, 1000^{\circ} \mathrm{C}$ & $C 14, C 36, C 15$ \\
Ti-66 Cr & $1300^{\circ} \mathrm{C}, 1200^{\circ} \mathrm{C}, 1000^{\circ} \mathrm{C}$ & $C 14, C 36, C 15 /(C 36)$ \\
Ti-67 Cr & $1300^{\circ} \mathrm{C}, 1200^{\circ} \mathrm{C}, 1000^{\circ} \mathrm{C}$ & $C 14, C 36,(C 36)$ \\
Ti-68 Cr & $1300^{\circ} \mathrm{C}, 1200^{\circ} \mathrm{C}, 1000^{\circ} \mathrm{C}$ & $C 14+\beta, C 36+\beta,(C 36)+\beta$ \\
Ti-69 Cr & $1300^{\circ} \mathrm{C}, 1200^{\circ} \mathrm{C}, 1000^{\circ} \mathrm{C}$ & $C 14+\beta, C 36+\beta,(C 36)+\beta$ \\
\hline Ternary Alloys & & \\
$33 \mathrm{Ti}-10 \mathrm{Fe}-57 \mathrm{Cr}$ & $1300^{\circ} \mathrm{C}$ & $C 14$ \\
$33 \mathrm{Ti}-20 \mathrm{Fe}-47 \mathrm{Cr}$ & $1300^{\circ} \mathrm{C}$ & $C 14$ \\
$33 \mathrm{Ti}-30 \mathrm{Fe}-37 \mathrm{Cr}$ & $1300^{\circ} \mathrm{C}$ & $C 14$ \\
$28 \mathrm{Ti}-05 \mathrm{Nb}-67 \mathrm{Cr}$ & $1300^{\circ} \mathrm{C}, 1200^{\circ} \mathrm{C}$ & $C 15 / C 36, C 15$ \\
$23 \mathrm{Ti}-10 \mathrm{Nb}-67 \mathrm{Cr}$ & $1300^{\circ} \mathrm{C}, 1200^{\circ} \mathrm{C}$ & $C 15, C 15$ \\
$18 \mathrm{Ti}-15 \mathrm{Nb}-67 \mathrm{Cr}$ & $1300^{\circ} \mathrm{C}, 1200^{\circ} \mathrm{C}$ & $C 15, C 15$ \\
$31.8 \mathrm{Ti}-4.5 \mathrm{~V}-63.7 \mathrm{Cr}$ & $1300^{\circ}, 1200^{\circ} \mathrm{C}, 1000^{\circ} \mathrm{C}$ & $C 14+\beta, C 15 / C 36+\beta, C 15+\beta$ \\
$32 \mathrm{Ti}-7 \mathrm{~V}-61 \mathrm{Cr}$ & $1300^{\circ}, 1200^{\circ} \mathrm{C}, 1000^{\circ} \mathrm{C}$ & $C 15, C 15 / C 36+\beta, C 15$ \\
$30.8 \mathrm{Ti}-7.5 \mathrm{~V}-61.7 \mathrm{Cr}$ & $1300^{\circ}, 1200^{\circ} \mathrm{C}$ & $\beta, C 15 / C 36+\beta$ \\
$29 \mathrm{Ti}-7 \mathrm{~V}-64 \mathrm{Cr}$ & $1300^{\circ}, 1200^{\circ} \mathrm{C}$ & $\beta, C 15 / C 36+\beta$ \\
$34 \mathrm{Ti}-4 \mathrm{Mo}-62 \mathrm{Cr}$ & $1300^{\circ}, 1200^{\circ} \mathrm{C}, 1000^{\circ} \mathrm{C}$ & $C 14+\beta, C 15 / C 36+\beta, C 15$ \\
$32 \mathrm{Ti}-4 \mathrm{Mo}-64 \mathrm{Cr}$ & $1300^{\circ}, 1200^{\circ} \mathrm{C}, 1000^{\circ} \mathrm{C}$ & $C 14+\beta, C 15 / C 36, C 15$ \\
$30 \mathrm{Ti}-4 \mathrm{Mo}-66 \mathrm{Cr}$ & $1300^{\circ}, 1200^{\circ} \mathrm{C}, 1000^{\circ} \mathrm{C}$ & $C 14+\beta, C 15 / C 36+\beta, C 15$ \\
\hline Two-Phase Binary Alloys & & \\
Ti-30 Cr & $800-1000^{\circ} \mathrm{C}$ & $C 15+\beta(\mathrm{Ti}-$ rich $)$ \\
Ti-40 Cr & $800-1000^{\circ} \mathrm{C}$ & $C 15+\beta(T i-$ rich $)$ \\
Ti-85 Cr & $1200^{\circ} \mathrm{C}, 1000^{\circ} \mathrm{C}$ & $C 14 / C 36+\beta(\mathrm{Cr}-$ rich $), C 15+\beta$ \\
Ti-87.5 Cr & $1200^{\circ} \mathrm{C}, 1000^{\circ} \mathrm{C}$ & $C 14 / C 36+\beta(\mathrm{Cr}-$ rich $), C 15+\beta$ \\
\hline
\end{tabular}




\section{RESULTS AND DISCUSSION}

Single-phase $\mathrm{TiCr}_{2}$

Nominal alloy compositions from $\mathrm{Ti}-62 \mathrm{at} \% \mathrm{Cr}$ to $\mathrm{Ti}-69 \mathrm{at} \% \mathrm{Cr}$ were selected to represent the single-phase $\mathrm{TiCr}_{2}$ alloys, and were annealed to isolate particular crystal structures. A range of approximately 2.5 at\% solubility was found, and three of the six alloys fell within the singlephase field to represent the stoichiometric and nonstoichiometric Laves phase (see Table I). Earlier work on these alloys suggested that the defect mechanism of the Ti-rich, nonstoichiometric $\mathrm{TiCr}_{2}$ Laves phases may be a combination of vacancies and anti-site substitutions [8]. These alloys were then indented to study the effect of stoichiometry and crystal structure.

Figure 2 displays the compositional dependence of the fracture toughness of the $C 36$ alloys at a load of $500 \mathrm{~g}$. The $C 14$ alloys did not show any apparent trend with respect to composition, and generally had slightly worse toughness values for the completely single-phase samples. The $C 15$ crystal structure was not fully attained in all the alloy samples for comparisons, but the toughness of the two $C 15$ samples available appeared to be higher (about $25 \%$ ) than in the hexagonal phases of the same composition.

The consistent and repeatable trend of the $C 36$ alloys revealed that a minimum in toughness occurs at the stoichiometric composition of $\mathrm{TiCr}_{2}$. Going off-stoichiometry imparts some resistance to cracking and offers the prospect of gaining some toughness when designing new alloy compositions. The possible vacancies in the nonstoichiometric compositions may aid the complicated atomic motions involved in the synchroshear deformation mechanism. Hazzledine [4] has proposed that a Shockley dislocation core can be split over two closelyspaced planes, where the atoms must change positions for synchroshear to occur in Laves phases. The vacancies facilitate this process without much dilatation of the crystal. Although no direct evidence of vacancies assisting the movement of dislocations has been reported, results from this study support such a theory.

Larger improvements in the fracture toughness were found in the alloys containing small amounts of a second phase, the bcc-beta phase. This phase was uniformly dispersed throughout the alloys and proved to be effective in reducing the crack lengths compared to the single-phase Laves samples. Crack interaction by the second phase and debonding of the $\mathrm{bcc} / \mathrm{TiCr}_{2}$ interface expends some of the crack energy, which leads to the greater toughness values. These findings hint that a two-phase system with large volume fractions of a second, more ductile phase will greatly improve the toughness, as will be discussed later.

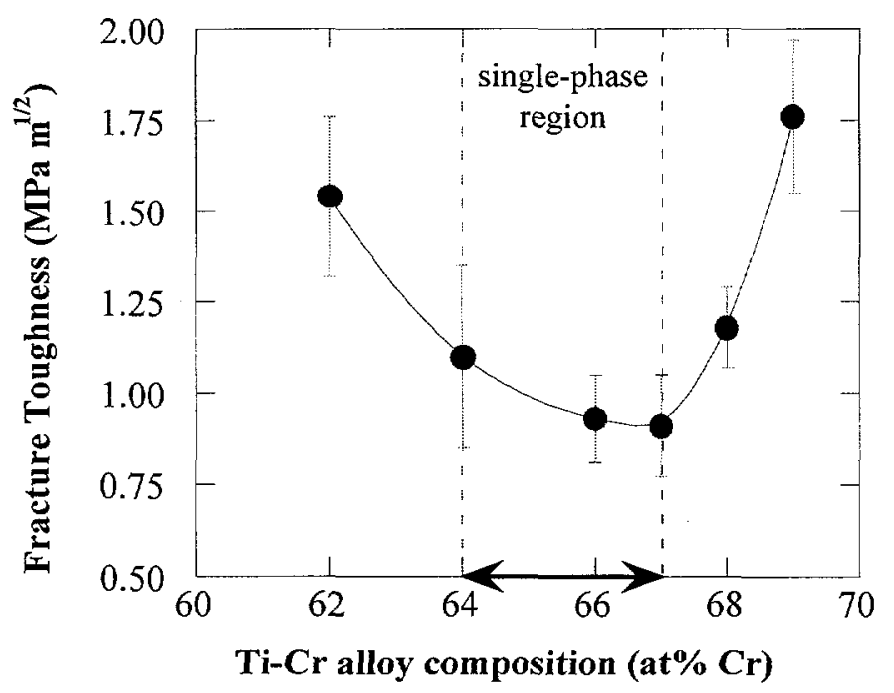

Figure 2. The compositional dependence of indentation fracture toughness for the $C 36 \mathrm{TiCr}_{2}$ alloys. The lowest toughness value occurs at the stoichiometric composition. Small amounts of a second phase improves the toughness. 
A systematic study of the effect of alloying element site occupancy was made with the $\mathrm{TiCr}_{2}$-base ternary alloys. These compositions were selected for the alloying element to substitute on specific sublattices of the $\mathrm{AB}_{2}$ Laves phase. The $\mathrm{Fe}$ atoms substituted for the $\mathrm{Cr}$ atoms on the $\mathrm{B}$-sublattice to form $\mathrm{Ti}(\mathrm{Fe}, \mathrm{Cr})_{2}$ Laves phases, while the $\mathrm{Nb}$ atoms substituted on the A-sublattice to form (Ti, $\mathrm{Nb}) \mathrm{Cr}_{2}$. V was found to reside primarily on the Cr-sublattice, and Mo could occupy both A and B sublattice sites (depending on the nominal alloy composition). Microprobe analysis and lattice constant measurements aided these determinations [9]. Alloying additions can also affect the electron concentration and thus, the stacking fault energies and crystal structures [10]. The different alloying elements did stabilize certain crystal structures, as listed in Table I.

The indentation results were analyzed as a function of alloying element, concentration of the alloying element, alloying element sublattice site occupancy, crystal structure, and microstructure. Fracture toughness values of the single-phase ternary alloys are plotted in Figure 3. Overall, the alloyed $\mathrm{TiCr}_{2}$ samples do not show dramatic improvements in toughness, but some interesting trends do appear. The $\mathrm{C} 14 \mathrm{Ti}(\mathrm{Fe}, \mathrm{Cr})_{2}$ alloys actually demonstrated worse cracking (not all data points plotted), while the $C 15(\mathrm{Ti}, \mathrm{Nb}) \mathrm{Cr}_{2}$ alloys had similar values as $\mathrm{TiCr}_{2}$, which then decreased with Nb-content. The Mo alloys had slightly higher toughness values, and the $\mathrm{V}$ alloys showed roughly $25 \%$ improvements over the binary $\mathrm{TiCr}_{2} \mathrm{Laves}_{\text {phase. }}$ These improvements in toughness occurred with relatively small concentrations of the alloying element, and may suggest that greater solubility may produce greater effects. Other Laves systems and processing techniques may extent the solubility limits for better toughening opportunities [11].

Alloying elements may extend the Laves phase field, or may induce the formation of a second phase. Some of the ternary alloys contained small amounts of the beta phase, and showed higher toughness values, as in the binary $\mathrm{TiCr}_{2}$ alloys with small amounts of beta. In addition, the ternary alloys demonstrated that the alloying effects on crystal structure should be considered. For instance, the cubic $C 15$ structure generally exhibited better toughness values

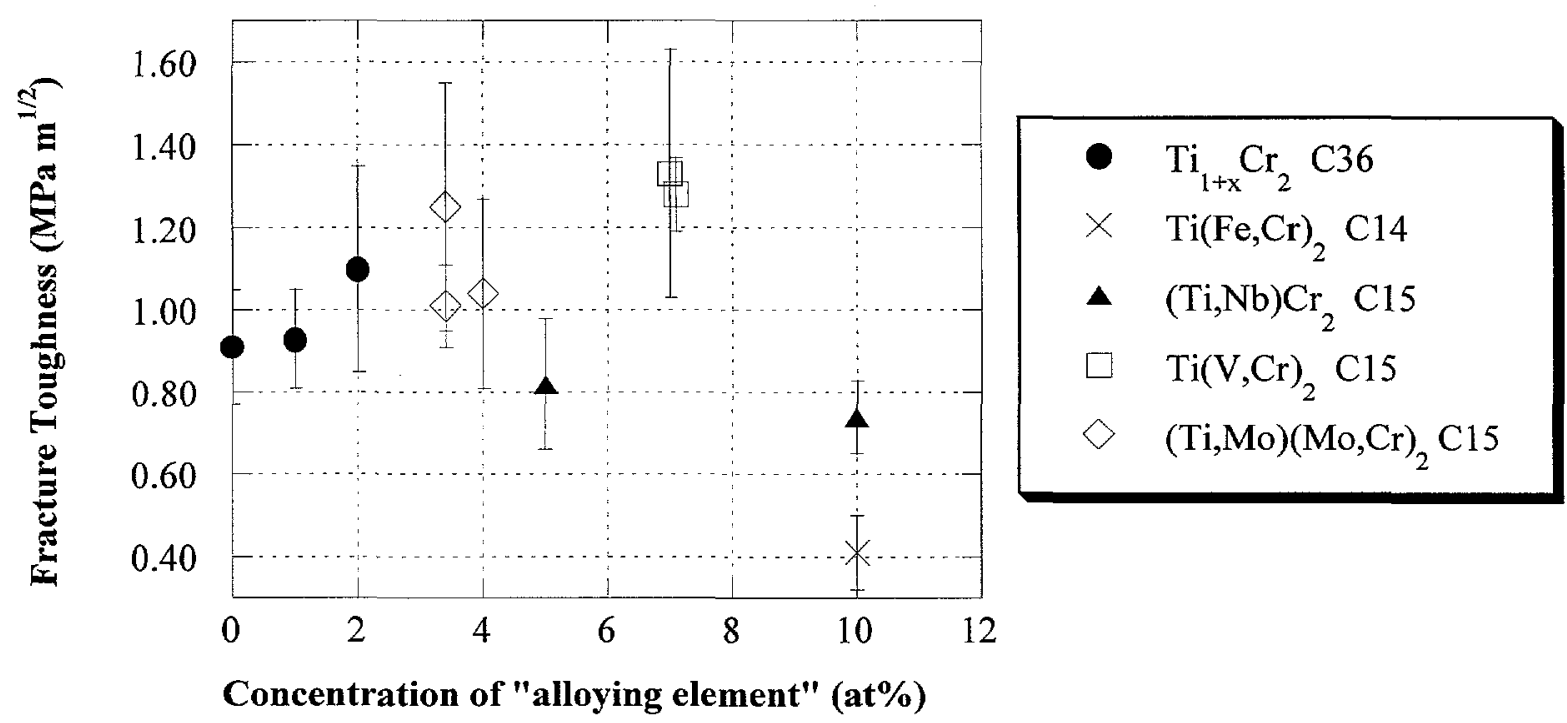

Figure 3. Fracture toughness of the (single-phase) $\mathrm{TiCr}_{2}$-base ternary Laves phases. 
than the hexagonal $C 14$ and $C 36$ structures. The cubic system offers more slip systems for deformation, and thus alloying elements could be selected to stabilize the $C 15$ structure. Such a technique has been employed for other intermetallics [12]. These approaches to alloying offer several strategies to improve the toughness of Laves phases.

Two-phase Ti-Cr alloys with $\mathrm{TiCr}_{2}$

The two-phase alloys discussed in this section have considerably larger volume fractions than those mentioned earlier, and in most cases, the bcc Ti-Cr solid solution is the matrix while the $\mathrm{TiCr}_{2}$ Laves phase is the reinforcement. The annealed Ti-rich and $\mathrm{Cr}$-rich two-phase $\mathrm{Ti}-\mathrm{Cr}$ alloys have quite different microstructures, as can be seen in Figure 4. In the Ti-rich alloys, the $\mathrm{TiCr}_{2}$ Laves phase precipitates from the beta solid solution as discrete particles, while the Cr-rich alloys, resemble eutectoid microstructures. The Laves phase in the $\mathrm{Cr}$-rich alloys actually-has a interconnected structure, as seen by TEM. These differences in microstructure have direct consequences on their respective mechanical properties.

The discrete $\mathrm{TiCr}_{2}$ particles have been found to deform under room-temperature compression [13], and demonstrate that under the appropriate conditions, the Laves phase can experience some room-temperature plastic deformation before fracture. On the other hand, the Cr-rich alloys fractured almost immediately under compression, most likely due to the network of the Laves phase. However, the Cr-rich alloys showed high hardness values and improved fracture toughness values.

At the usual load of $500 \mathrm{~g}$, no cracks were formed and an indentation load of $15 \mathrm{~kg}$ had to be used in order to initiate cracks for toughness measurements of the Cr-rich, two-phase alloys. The fracture toughness values were roughly five to seven times greater than that of the singlephase $\mathrm{TiCr}_{2}$ alloys. Crack blunting, deflection, and bridging were identified by SEM. The dual phase microstructure disrupted the propagation of the cracks, and decohesion of the bcc/Laves phase interface occurred. The Ti-rich alloys did not experience cracking with the indentation load of $15 \mathrm{~kg}$, although the larger sized $\mathrm{TiCr}_{2}$ particles did show some cracks. Even better mechanical properties are expected with optimized microstructures, such as a uniform dispersion of fine Laves phases in a ductile matrix. Other studies [14,15] have shown the Laves phase to be a potent strengthener in a two-phase system.

\section{SUMMARY AND CONCLUSIONS}

Within the single-phase $\mathrm{TiCr}_{2}$ Laves field, the stoichiometric composition displayed the lowest fracture toughness values. Constitutional defects found in the nonstoichiometric compositions may be assisting the synchroshear deformation mechanism. The $\mathrm{Fe}$ and $\mathrm{Nb}$ additions to $\mathrm{TiCr}_{2}$ did not show improvements in the toughness, but the limited solubility of Mo and $\mathrm{V}$ resulted in slightly higher toughness values. The ternary alloys also suggested that the toughness may be improved if the alloying element stabilizes the $C 15$ crystal structure. The largest improvements in toughness were seen with the two-phase alloys. Incorporation of a more ductile phase enables crack bridging, crack deflection, and interface debonding to occur. Development of the Laves phases may best be approached by a combination of selecting the appropriate Laves phase composition and optimizing the microstructure of two-phase systems. 

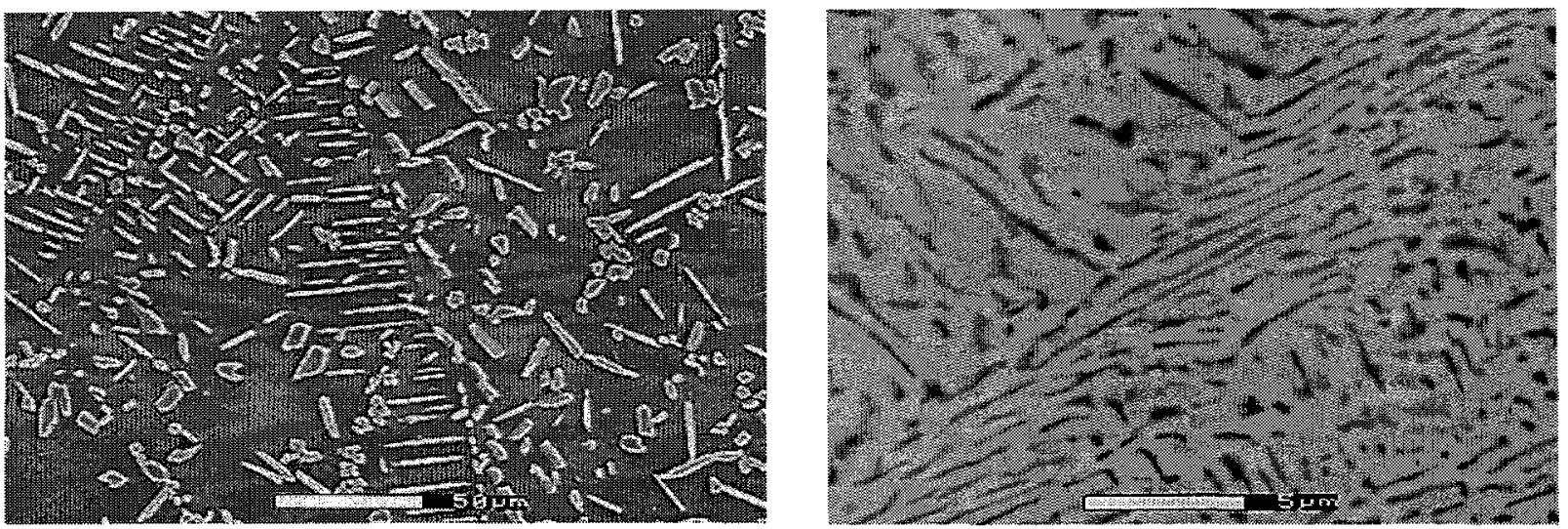

Figure 4. (a) SEM of the Ti-30 Cr two-phase alloy. The $\mathrm{TiCr}_{2}$ Laves phase precipitates out as lath-shaped structures. (b) SEM of the Ti-80 $\mathrm{Cr}$ two-phase alloy, where the darker phase is the $\mathrm{TiCr}_{2}$. Note the difference in microstructural size scale and morphology.

\section{ACKNOWLEDGEMENTS}

This research has been supported by the Division of Materials Sciences, Office of Basic Energy Sciences, United States Department of Energy, grant \#DE-FG02-90ER45426. The author would also like to thank Dan J. Thoma for his insight and useful comments.

\section{REFERENCES}

1. K. Inoue and K. Tachikawa, IEEE Trans. Magn. MAG-13, 840 (1977).

2. J.D. Livingston and E.L. Hall, J. Mater. Res. 5, 5 (1990).

3. F. Chu and D.P. Pope, Mat. Sci. Eng., A170, 39 (1993).

4. P.M. Hazzledine, K.S. Kumar, D.B. Miracle, and A.G. Jackson in High-Temperature Ordered Intermetallic Alloys V, edited by I. Baker, J.D. Whittenberger, R. Darolia, and M.H. Yoo (Mater. Res. Soc. Symp. Proc. 288, Pittsburgh, PA, 1992) pp. 591-596.

5. K.S. Kumar and D.B. Miracle, Intermetallics 2, 257 (1994).

6. J.D. Livingston, phys. stat. sol. (a) 131, 415 (1992).

7. G.R. Anstis, P. Chantikul, B.R. Lawn, and D.B. Marshall, J. Am. Cer. Soc. 64, 533 (1981).

8. K.C. Chen, S.M. Allen, and J.D. Livingston in High-Temperature Ordered Intermetallic Alloys VI, edited by J.A. Horton, I. Baker, S. Hanada, R.D. Noebe, and D.S. Schwartz (Mater. Res. Soc. Symp. Proc. 364, Pittsburgh, PA, 1994) pp. 1401-1406.

9. K.C. Chen, S.M. Allen, and J.D. Livingston, work in progress.

10. F. Laves and H. Witte, Metallwertschaft 15, 840 (1936).

11. J.C. Foley, D.J. Thoma, and J.H. Perepezko, Metall. Et Mater. Trans. 25, 230 (1994).

12. S. Zhang, J.P. Nic, and D.E. Mikkola, Scripta Metall. Et Mater. 24, 1099 (1990).

13. K.C. Chen, S.M. Allen, and J.D. Livingston in High-Temperature Ordered Intermetallic Alloys V, edited by I. Baker, J.D. Whittenberger, R. Darolia, and M.H. Yoo (Mater. Res. Soc. Symp. Proc. 288, Pittsburgh, PA, 1992) pp. 373-378.

14. M.D. Bhandarkar, M.S. Bhat, V.F. Zackay, and E.R. Parker, Metall. Trans., 6A, 1281 (1975).

15. T. Takasugi, S. Hanada, and k. Miyamoto, J. Mater. Res. 8, 3069 (1993). 